\title{
Selfing and outcrossing in a parasitic hermaphrodite helminth (Trematoda, Echinostomatidae)
}

\author{
SANDRINE TROUVÉ, FRANÇOIS RENAUD†, PATRICK DURAND \& JOSEPH \\ JOURDANE* \\ Centre de Biologie et d'Écologie Tropicale et Méditerranéenne, Laboratoire de Biologie Animale, CNRS URA 698, \\ Université de Perpignan, Avenue de Villeneuve, 66860 Perpignan Cedex and + Laboratoire de Parasitologie \\ Comparée, CNRS URA 698, USTL Montpellier II, Place E. Bataillon, 34095 Montpellier Cedex 05, France
}

\begin{abstract}
Echinostomes are simultaneous hermaphrodite trematodes, parasitizing the intestine of vertebrates. They are able to self- and cross-inseminate. Using electrophoretic markers specific for three geographical isolates (strains) of Echinostoma caproni, we studied the outcrossing rate from a 'progeny-array analysis' by comparing the mother genotype with those of its progeny. In a simultaneous infection of a single mouse with two individuals of two different strains, each individual exhibits an unrestricted mating pattern involving both self- and cross-fertilization. The association in mice of two adults of the same strain and one adult of another strain shows a marked mate preference between individuals of the same isolate. From mice coinfected with one parent of the three isolates, each parent was shown to be capable of giving and receiving sperm to and from at least two different partners. Mating system polymorphism in our parasitic model is thus discussed in the context of the theories usually advanced.
\end{abstract}

Keywords: assortative mating, Echinostoma caproni, genetical markers, multiple fertilizations, selfing, sperm exchanges.

\section{Introduction}

The occurrence in plants and animals of functionally hermaphrodite organisms offers an ideal model to examine the evolution and maintenance of two different mating systems (selfing and outcrossing). Is it more advantageous to invest completely in their own genome (selfing) or to look for a partner for exchange of genetic material (outcrossing) with the risk of not finding one? Two main hypotheses are usually proposed to explain the evolution of these two breeding systems. In organisms which have a low probability of meeting a partner, that is, species with low mobility or population density (Tomlinson, 1966; Ghiselin, 1969, 1974; Charnov et al., 1976), selfing will be favoured. On the other hand, the homozygosity resulting from selfing would generate a genetic load by the accumulation of deleterious recessive mutations which would promote outcrossing (Futuyma, 1986; Maynard Smith, 1989). Biologists have studied this topic for a long time, but

\footnotetext{
*Correspondence.
}

much more so in plants (see Jain, 1976 for review) than animals. The breeding systems of most hermaphrodite animals remain almost unknown, except for those of pulmonates (Jarne \& Charlesworth, 1993; Jarne et al., 1993 for review) and ascidians (Ryland \& Bishop, 1990; Bishop \& Ryland, 1993) which are well documented.

The parasitic worms, especially the platyhelminths, which are almost all hermaphrodites, represent an ideal model to examine whether the polymorphous mating systems known in plants have animal counterparts. The biology of the parasites is influenced by a double constraint: (i) the obligatory conquest of a living environment which often produces parasite populations in low densities and patchy distributions (Renaud et al., 1992) and (ii) the need within this host to find a mate for outcrossing and avoiding inbreeding depression (Price, 1977, 1980). These two factors seem important to understand the evolution of breeding systems such as selfing and outcrossing. But few studies on the evolution of mating systems have been conducted in helminth parasites. Data obtained on the genetic 
structure of populations of cestodes (Renaud et al., 1983, 1986; Renaud \& Gabrion, 1988) and trematodes (Reversat et al., 1989) have shown that natural populations of such organisms seem panmictic. In other respects, experimental research using radioactive isotopes has shown sperm exchanges in digenetic trematodes (Nollen, 1983, 1990, 1993). Nevertheless, none of these studies estimates the rates of self-fertilization and cross-fertilization in this wide group of parasites. We present and discuss in this paper the results of an experimental study on the evolution of selfing vs. outcrossing presented by these parasites in different situations of mixed infections.

\section{Materials and methods}

\section{Model}

The parasite complex Echinostoma caproni used in this study consists of three geographical strains, the first originating from Madagascar, the second from Egypt and the third from Cameroon. According to Christensen et al. (1990), these three strains (geographical isolates in fact) belong to the same species, E. caproni. They freely interbreed under experimental conditions. In the text, the Madagascan strain will be called $E$. $c$, the Egyptian strain $E$. $l$ and the Cameroonian strain $E$. $k$.

The life cycle of $E$. caproni includes three successive hosts (Huffman \& Fried, 1990): the first intermediate host (mollusc) where rediae and cercariae develop, the second intermediate host (mollusc or amphibian) where cercariae transform into infectious metacercariae, and the definitive host (mammal or bird) where metacercariae develop into sexually mature adults. In the laboratory, E. caproni is routinely cycled through two hosts: the snail Biomphalaria pfeifferi which acts as first and second intermediate host and the mouse (Swiss OF1 stock) which acts as definitive host.

\section{Genetic analysis}

The three strains are three different genetic entities which can be identified by three diagnostic loci. These are the phosphoglucomutase (Pgm, EC 5.4.2.2), the glucose-6-phosphate isomerase ( $\mathrm{Gpi}$, EC 5.3.1.9) and the mannose-6-phosphate isomerase (Mpi, EC 5.3.1.8). The first two loci (i.e. Pgm and Gpi) were described by Voltz et al. (1986, 1987, 1988), the third was discovered by us. The codominance and Mendelian segregation of these alleles allow us to distinguish between selfed and outcrossed offspring and then to calculate the rate of selfing. Starch electrophoresis and histochemical tests on these isoenzymes were performed using the technique of Pasteur et al. (1987).

\section{Parasite distribution in the mouse intestine}

Metacercariae were obtained from experimentally infected snails by dissection and were fed to mice via stomach tubes. At 20 days postinfection, the small intestine of the mice was opened and divided into six equal sections, and the distribution of adult echinostomes along the intestine was noted. Parasites were recovered individually and their genotypes systematically determined by electrophoresis. The different experiments carried out are presented in Table 1. This study was performed using mixed infections with the two strains $E . c$ and $E . l$.

\section{Genetic exchanges between strains}

Metacercarial infections and recovery of adults followed the previous procedure. The uterus of each parasite was then torn to release the eggs. The eggs of each offspring developed in about 15 days in spring water at $27^{\circ} \mathrm{C}$ in a Petri dish and, stimulated by artificial light, the miracidia (infecting larvae of the first intermediate host) hatched. Thirty miracidia of each laying were separately brought into contact with each mollusc. Because the parasite-mollusc compatibility was not absolute, some molluscs did not become infected. Consequently, the number of offspring analysed for each adult corresponds to the number of infected molluscs. Because clonal multiplication takes place in the snail, we could obtain a sufficient quantity of parasitic tissues (rediae) 25 days after the infection to carry out electrophoresis. The genetic exchanges were assessed by comparison between parent and offspring genotypes. The different infections conducted to estimate the rates of selfing and outcrossing are shown in Table 1.

\section{Data analysis}

The Fisher exact test (Sokal \& Rolf, 1981), developed by Raymond \& Rousset (1995), was used to compare the rate of outcrossing amongst the different experiments. This statistical analysis was performed using the program GENEPOP (Raymond \& Rousset, 1995). Because of the complexity of our data (several infection types and samples) the sequential Bonferroni method was used to adjust the significance level (Rice, 1989). For the global statistics we also calculated the $P$-values according to 
Table 1 Design of the experiments

\begin{tabular}{lc}
\hline $\begin{array}{l}\text { No. individuals of } \\
\text { each strain infecting } \\
\text { each mouse }\end{array}$ & $\begin{array}{c}\text { No. experiments } \\
\text { performed }= \\
\text { no. mice infected }\end{array}$ \\
\hline $\begin{array}{l}\text { Distribution of parasites in small intestine } \\
5 E . c+5 E . l\end{array}$ & 11 \\
$10 E . c+10 E . l$ & 10 \\
Genetic exchanges between different strains & \\
$1 E . c+1 E . l$ & $7 \dagger$ \\
$1 E . c+1 E . k$ & $7 \dagger$ \\
$1 E . c+1 E . c+1 E . l$ & $3 \dagger$ \\
$1 E . c+1 E . l+1 E . k$ & $4 \dagger$ \\
\hline
\end{tabular}

E. c, Madagascan strain of Echinostoma caproni; E. l, Egyptian strain of E. caproni; E. $k$, Cameroonian strain of E. caproni.

†For each infection type, 30 offspring (rediae) of each adult were genetically determined at three loci.

Fisher's method for combining independent test results (Manly, 1987).

\section{Results}

\section{Parasite distribution in the mouse intestine}

The distribution of 198 individual parasites (98 E. c and $100 E . l$ ) was examined for the two infection types (Table 1). Nearly all the Echinostoma (i.e. $>90$ per cent) colonized the lower third of the small intestine (the ileum) (Fig. 1). Moreover, there was no significant difference in the distribution of the two strains. Consequently, there is no habitat segregation for these parasites, so that the probability of meeting between and within strains is identical.

\section{Genetic exchanges between the strains}

Simultaneous infection with one E. c and one E. 1. The results indicate a high interfecundity level as the outcrossing rates varied from 41 to 100 per cent for $E$. $c$ and from 33 to 100 per cent for $E$. $l$, except for experiment 5 where pure selfing occurred for both individuals (Table 2). The data were excluded when both individuals totally selfed as this could have been caused by no meeting and pairing between the mates in the host habitat. Combination of the $P$-values from six replicates using the Fisher's method gave a significant result $(P=0.0026)$ which would indicate that these two strains allocate the autosperm to their offspring in different ways. However, note that this statistical significance may

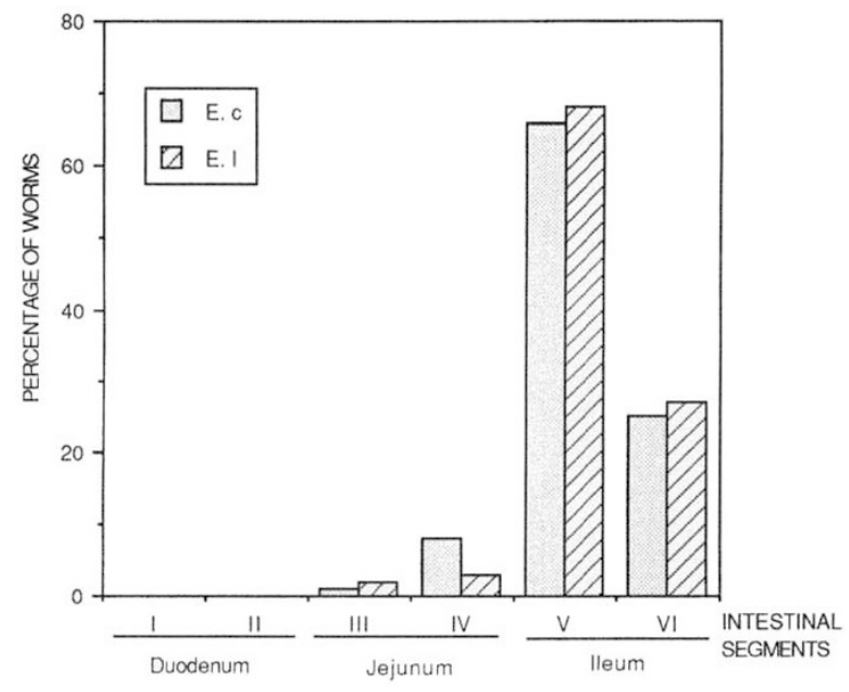

Fig. 1 Distribution of the two strains of Echinostoma caproni in the small intestine of mice. The data from the $E$. $c$. and $E$. $l$. infections, performed with 10 and 20 metacercariae, respectively, have been pooled. E. $c$ : Madagascar strain of $E$. caproni, E. $l$ : Egyptian strain of $E$. caproni.

be attributed to the result of one experiment (i.e. experiment 1 , Table 2 ).

Simultaneous infection with one $\mathrm{E}$. c and one E. $\mathrm{k}$. A high variability was shown in the outcrossing proportions with values from 48 to 86 per cent for $E$. $c$ and from 0 to 100 per cent for $E$. $k$, except for experiments 8 and 9 where pure selfing was observed for both individuals (Table 3 ). These two strains also seemed to allocate the allosperm to their offspring in different ways (combined $P$-values: $P=0$, Fisher's method). However, as mentioned above, this result is the consequence of a single experiment (i.e. experiment 14 , Table $3, P=0$ ).

Simultaneous infection with two E. c and one E. 1 . In this situation, all the $E$. $l$ individuals outcrossed (Table 4). The results seem to show a higher rate of self-fertilization for both $E$. $c$ (i.e. $77-100$ per cent) than cross-fertilization (i.e. $0-23$ per cent). However, in these three experiments the outcrossing rate is certainly underestimated as the genotypes coming from outcrossing between two individuals from the same strain (i.e. between two $E$. $c$ individuals) cannot be distinguished by the isoenzymatic markers. Table 5 shows the comparison tests of the mating behaviour of $E$. $c$ when it is associated with (i) a single mate belonging to another genetic strain (i.e. $E$. $l$ or $E$. $k$ ) or (ii) a partner belonging to its 
Table 2 Comparison of the proportions of outcrossed offspring generated by each parent of a pair $E . c+E . l$

\begin{tabular}{|c|c|c|c|c|}
\hline $\begin{array}{l}\text { Experiment } \\
\text { no. }\end{array}$ & $\begin{array}{l}\text { Strain of } \\
\text { parents }\end{array}$ & $\begin{array}{l}\text { No. offspring } \\
\text { analysed }\end{array}$ & $\begin{array}{l}\text { No. outcrossed } \\
\text { offspring }\end{array}$ & $\begin{array}{l}P \text { (Fisher's } \\
\text { exact test) }\end{array}$ \\
\hline 1 & $\begin{array}{l}E . c \\
E . l\end{array}$ & $\begin{array}{l}19 \\
22\end{array}$ & $\begin{array}{l}11(58 \%) \\
22(100 \%)\end{array}$ & $0.0008^{*}$ \\
\hline 2 & $\begin{array}{l}E . c \\
E . l\end{array}$ & $\begin{array}{l}17 \\
24\end{array}$ & $\begin{array}{l}7(41 \%) \\
8(33 \%)\end{array}$ & 0.52 \\
\hline 3 & $\begin{array}{l}\text { E. } c \\
\text { E. } l\end{array}$ & $\begin{array}{l}21 \\
26\end{array}$ & $\begin{array}{l}16(76 \%) \\
24(92 \%)\end{array}$ & 0.217 \\
\hline 4 & $\begin{array}{l}\text { E. } c \\
\text { E. } l\end{array}$ & $\begin{array}{l}18 \\
25\end{array}$ & $\begin{array}{l}12(67 \%) \\
11(44 \%)\end{array}$ & 0.127 \\
\hline 5 & $\begin{array}{l}\text { E. } c \\
\text { E. } l\end{array}$ & $\begin{array}{l}20 \\
18\end{array}$ & $\begin{array}{l}0(0 \%) \\
0(0 \%)\end{array}$ & - \\
\hline 6 & $\begin{array}{l}\text { E. } c \\
\text { E. } l\end{array}$ & $\begin{array}{l}22 \\
18\end{array}$ & $\begin{array}{l}18(82 \%) \\
18(100 \%)\end{array}$ & 0.114 \\
\hline 7 & $\begin{array}{l}\text { E. } c \\
\text { E. } l\end{array}$ & $\begin{array}{l}20 \\
18\end{array}$ & $\begin{array}{l}20(100 \%) \\
16(89 \%)\end{array}$ & 0.218 \\
\hline
\end{tabular}

E. c, Madagascan strain of Echinostoma caproni; E. l, Egyptian strain of $E$. caproni.

*Significant difference after the application of Bonferroni sequential test.

own strain (i.e. E. c) and a partner $E$. $l$. The test shows that the $E$. $c$ individuals manage the sperm in very different ways depending on the mates present. Thus, when associated with $E$. $l$ or with $E . k, E . c$ used the same quantity of allosperm to create its offspring (Tables 2 and 3). However, when associated with a mate of its own strain, $E$. $c$ changed its behaviour by reducing the investment of allosperm coming from $E . l$ (Table 4).

Simultaneous infection with one E. c, one E. 1 and one E. k. All fertilization permutations between the entities were seen (Table 6). Moreover, multiple fertilizations occurred; that is, for each adult some of the offspring were selfed and others were crossed with two different types of allosperm. Multiple fertilizations occurred for all the individuals in experiment 20 (Table 6).

\section{Discussion}

\section{Parasite distribution in the mouse intestine}

The two strains $E . c$ and $E$. $l$ were localized exclusively in the proximal segment of the mouse ileum which confirms the observations on the same species by Hosier \& Fried (1991). The gregarious behaviour of echinostome adults may be attributable to a chemoattractant (free sterols) released by the worms (Fried et al., 1980). Habitat selection within host tissues has been explained (Holmes, 1979) mainly by the necessity for the parasites (i) to live in a restrictive microhabitat (niche) consistent with their specific physiological requirements and (ii) to find a mate within the host (Rodhe, 1979).

\section{Genetic exchanges between the strains}

Previous studies on helminth reproduction (cestodes, Kumaratilake et al., 1986; and trematodes, Nollen, 1983, 1990, 1993) have been restricted to qualitative analysis of inseminations (self- vs. crossinsemination) between individuals. Here, the evolution of the selfing rate in parasitic helminths was studied by genetic characterization of offspring which revealed the potential for both self- and crossfertilization in our three strains. Even when associated with another mate, the individuals from each isolate are able to self-fertilize.

The selfing rates obtained after associations of 
Table 3 Comparison of the proportions of outcrossed offspring generated by each parent of a pair $E . c+E . k$

\begin{tabular}{|c|c|c|c|c|}
\hline $\begin{array}{l}\text { Experiment } \\
\text { no. }\end{array}$ & $\begin{array}{l}\text { Strain of } \\
\text { parents }\end{array}$ & $\begin{array}{l}\text { No. offspring } \\
\text { analysed }\end{array}$ & $\begin{array}{l}\text { No. outcrossed } \\
\text { offspring }\end{array}$ & $\begin{array}{l}P \text { (Fisher's } \\
\text { exact test) }\end{array}$ \\
\hline \multirow[t]{2}{*}{8} & E. $c$ & 24 & $0(0 \%)$ & \multirow[t]{2}{*}{ - } \\
\hline & E. $k$ & 20 & $0(0 \%)$ & \\
\hline \multirow[t]{2}{*}{9} & E. $c$ & 15 & $0(0 \%)$ & \multirow[t]{2}{*}{ - } \\
\hline & E. $k$ & 7 & $0(0 \%)$ & \\
\hline \multirow[t]{2}{*}{10} & E. $c$ & 23 & $11(48 \%)$ & \multirow[t]{2}{*}{1} \\
\hline & E. $k$ & 12 & $5(42 \%)$ & \\
\hline \multirow[t]{2}{*}{11} & E. $c$ & 21 & $18(86 \%)$ & \multirow[t]{2}{*}{0.23} \\
\hline & E. $k$ & 21 & $21(100 \%)$ & \\
\hline \multirow[t]{2}{*}{12} & E. $c$ & 18 & $12(67 \%)$ & \multirow{2}{*}{0.715} \\
\hline & E. $k$ & 15 & $10(15 \%)$ & \\
\hline \multirow[t]{2}{*}{13} & E. $c$ & 8 & $4(50 \%)$ & \multirow[t]{2}{*}{0.079} \\
\hline & E. $k$ & 7 & $0(0 \%)$ & \\
\hline \multirow[t]{2}{*}{14} & E. $c$ & 18 & $14(78 \%)$ & \multirow[t]{2}{*}{$0^{*}$} \\
\hline & E. $k$ & 14 & $0(0 \%)$ & \\
\hline
\end{tabular}

E. c, Madagascan strain of Echinostoma caproni; $E$. $k$, Cameroonian strain of $E$. caproni.

*Significant difference after the application of Bonferroni sequential test.

Table 4 Number of outcrossed offspring generated by each parent of a group of three worms: $2 E . c+1 E . l$

\begin{tabular}{lccc}
\hline $\begin{array}{l}\text { Experiment } \\
\text { no. }\end{array}$ & $\begin{array}{c}\text { Strain of } \\
\text { parents }\end{array}$ & $\begin{array}{c}\text { No. offspring } \\
\text { analysed }\end{array}$ & $\begin{array}{c}\text { No. outcrossed } \\
\text { offspring }\end{array}$ \\
\hline 15 & $E . c$ & 13 & $3(23 \%)$ \\
& $E . c$ & 6 & $1(17 \%)$ \\
& E. $l$ & 14 & $14(100 \%)$ \\
16 & & & \\
& E. $c$ & 16 & $3(19 \%)$ \\
& E. $c$ & 17 & $2(12 \%)$ \\
17 & E. $l$ & 20 & $20(100 \%)$ \\
& E. $c$ & 19 & $0(0 \%)$ \\
& E. $c$ & 19 & $0(0 \%)$ \\
& E. $l$ & 8 & $8(100 \%)$ \\
\hline
\end{tabular}

E. c, Madagascan strain of Echinostoma caproni; E. l, Egyptian strain of E. caproni.

two strains were, on average, very similar from one strain to another in spite of individual variation (Tables 2 and 3) and did not show any particular pattern of reproduction for the echinostomes. In most cases, the offspring were mixed, i.e. partly selfed and partly outcrossed. In experimental conditions, these parasites showed a three-way mixedmating model because they may adopt either the male or female role, or they may ignore their partner and continue to self-fertilize. Many parasites (such as echinostomes) have low mobility, often evolve in low density populations (including the limiting case of one parasite per host) and behave as pioneers each time they colonize a new host. Thus, self-fertilization ensures their reproduction (Price, 1977) and can provide a survival mechanism by maintaining the genotype for several generations until a partner appears for cross-fertilization within the host. However, the high outcrossing potentiality of these organisms may reflect a major disadvantage of selfing, i.e. inbreeding depression (Charlesworth \& Charlesworth, 1987). A mixed-mating system could be maintained by an equilibrium between conditions which select selfing or outcrossing.

This study also provides general data on the potentiality of sperm management in parasites. Indeed, in infections with three individuals each belonging to a different strain (Table 6), multiple fertilizations are possible. Hence, an individual remains receptive to others after an initial insemina- 
Table 5 Comparison of the proportions of outcrossed offspring generated by a parent $E . c$ associated with a partner $E . l$ and the proportions of outcrossed offspring generated by a parent $E . c$ associated with a partner $E$. $k$ or with two partners $(1 E . c$ and $1 E . l)$

\begin{tabular}{lcccccc}
\hline & \multicolumn{5}{c}{$P$-values (Fisher's exact test) $(1 E . c+E . l)$ for experiment no. } \\
\cline { 2 - 7 } $\begin{array}{l}\text { Experiment } \\
\text { no. }\end{array}$ & 1 & 2 & 3 & 4 & 6 & 7 \\
\hline $1 E . c+1 E$. & & & & & & \\
10 & 0.34411 & 0.5192 & 0.06762 & 0.22135 & 0.01332 & $0.00018^{*}$ \\
11 & 0.07770 & 0.0064 & 0.69350 & 0.25146 & 1 & 0.23223 \\
12 & 0.73982 & 0.1814 & 0.49692 & 1 & 0.14080 & 0.00634 \\
13 & 1 & 1 & 0.21276 & 0.46817 & 0.16059 & 0.00368 \\
14 & 0.18142 & 0.0382 & 1 & 0.26493 & 1 & 0.04384 \\
$2 E . c+1 E . l$ & & & & & & \\
15 & 0.04283 & 0.1578 & $0.00134^{*}$ & $0.00257^{*}$ & $0.00006^{*}$ & $0^{*}$ \\
16 & $0.00022^{*}$ & 0.0775 & $0^{*}$ & $0.00071^{*}$ & $0^{*}$ & $0^{*}$ \\
17 & $0^{*}$ & $0^{*}$ & $0^{*}$ & $0^{*}$ & $0^{*}$ & $0^{*}$ \\
\hline
\end{tabular}

E. c, Madagascan strain of Echinostoma caproni; E. l, Egyptian strain of $E$. caproni; E. $k$, Cameroonian strain of E. caproni.

*Significant difference after the application of Bonferroni sequential test.

Table 6 Proportions of outcrossed offspring generated by each parent of a group of three worms: $1 E . c+1 E . l+1 E . k$

\begin{tabular}{lccccc}
\hline $\begin{array}{l}\text { Experiment } \\
\text { No. }\end{array}$ & $\begin{array}{c}\text { Strain } \\
\text { of the } \\
\text { parents }\end{array}$ & $\begin{array}{c}\text { No. } \\
\text { offspring } \\
\text { analysed }\end{array}$ & $\begin{array}{c}\text { No. hybrid } \\
\text { offspring } \\
(E . c+E . l)\end{array}$ & $\begin{array}{c}\text { No. hybrid } \\
\text { offspring } \\
(E . c+E . k)\end{array}$ & $\begin{array}{c}\text { No. hybrid } \\
\text { offspring } \\
(E . l+E . k)\end{array}$ \\
\hline 18 & $E . c$ & 21 & $0(0 \%)$ & $0(0 \%)$ & - \\
& $E . l$ & 19 & $0(0 \%)$ & - & $0(0 \%)$ \\
19 & $E . k$ & 15 & - & $0(0 \%)$ & $0(0 \%)$ \\
& $E . c$ & 20 & $0(0 \%)$ & $7(35 \%)$ & - \\
20 & $E . l$ & 19 & $2(11 \%)$ & - & $2 .(11 \%)$ \\
& $E . k$ & 22 & - & $5(23 \%)$ & $17(77 \%)$ \\
& $E . c$ & 22 & $11(50 \%)$ & $1(5 \%)$ & - \\
21 & $E . l$ & 16 & $5(31 \%)$ & - & $3(19 \%)$ \\
& $E . k$ & 18 & - & $4(22 \%)$ & $9(50 \%)$ \\
& $E . c$ & 21 & $11(52 \%)$ & $0(0 \%)$ & - \\
& $E . l$ & 23 & $22(96 \%)$ & - & $0(0 \%)$ \\
& $E . k$ & 12 & - & $0(0 \%)$ & $0(0 \%)$ \\
\hline
\end{tabular}

E. c, Madagascan isolate of Echinostoma caproni; E. l, Egyptian isolate of $E$. caproni; E. $k$, Cameroonian isolate of $E$. caproni.

tion and may pursue outcrossing as a male or female, as shown in gastropods (Rollinson et al., 1989). It seems that these parasites are able to manage, in time, the sperm allocation for their female function.

Sperm allocation seems identical for one $E . c$ associated with one $E$. $l$ or one $E$. $k$, or simultaneously with one $E$. $l$ and one $E$. $k$. However, the outcrossing rate for two $E$. $c$ during infections with one $E$. $l$ (Table 5) seems lower than those observed in the other crossing experiments. We suggest (i) a preferential crossing between the $E$. $c$ individuals, 
i.e. homogamy phenomenon (Hartl \& Clark, 1989) or (ii) a differential spermatic allocation between intra- and interstrain allosperms (i.e. spermatic competition). In other words, although the $E$. $c$ individual has been fertilized by two other partners $(E$. $c$ and $E . l$ ), it produces offspring preferentially from the allosperm of its own strain.

The data from Table 4 seem consistent with the second hypothesis because in two out of three experiments, the two $E$. $c$ were fertilized by $E$. $l$, but there was a preferential investment in intrasperm. This lower investment in foreign sperm may also reflect a reproductive isolation between these Echinostoma strains. Thus the mating systems that we have shown in the E. caproni complex are probably the consequence of selective pressures imposed by the life cycle patterns of these parasitic helminths.

\section{Acknowledgements}

We are indebted to I. Teboul, B. Dejean, M.-T. Almeras and J.-R. Pages for excellent technical assistance and T. de Meeüs, P. Jarne and S. Morand for helpful discussions. We thank C. Wilkinson for assistance with English translation. We would like to thank the two anonymous referees for helpful comments that greatly improved the manuscript. This work received financial support from the CNRS (Sciences de la Vie).

\section{References}

BISHOP, J. D. D. AND RYLAND, J. s. 1993. Enzyme electrophoretic evidence for the prevalence of outcrossing in the hermaphroditic brooding ascidian Dendrodoa grossularia (Chordata, Urochordata). J. Exp. Mar. Biol. Ecol., 168, 149-165.

CHARLESWORTH, D. AND CHARLESWORTH, B. 1987. Inbreeding depression and its evolutionary consequences. Ann. Rev. Ecol. Syst., 18, 237-268.

CHARNOV, E. L., MAYNARD SMITH, J. AND BULL, J. J. 1976. Why be an hermaphrodite? Nature, 263, 125-126.

CHRISTENSEN, N. O., FRIED, B. AND KANEV, 1. 1990. Taxonomy of 37-collar spined Echinostoma (Trematoda: Echinostomatidae) in studies on the population regulation in experimental rodent hosts. Angew. Parasitol., 31, $127-130$.

FRIED, B., TANCER, R. B. AND FLEMING, S. J. 1980. In vitro pairing of Echinostoma revolutum (Trematoda) metacercariae and adults, and characterization of worm products involved in chemoattraction. J. Parasitol., 66, 1014-1018.

FUTUYMA, D. J. 1986. Evolutionary Biology, 2nd edn. Sinauer, Sunderland, MA.

GHISELIN, M. T. 1969. The evolution of hermaphroditism among animals. Q. Rev. Biol., 44, 189-208.
GHISELIN, M. T. 1974. The Economy of Nature and the Evolution of Sex. University of California Press, Berkeley.

HARTL, D. L. AND ClARK, A. G. 1989. Principles of Population Genetics, 2nd edn. Sinauer, Sunderland, MA.

Holmes, J. C. 1979. Parasites populations and host community structure. In: Nickol, B. B (ed.) Host-Parasites Interfaces, pp. 27-46. Academic Press, New York.

HOSIER, D. W. AND FRIED, B. 1991. Infectivity, growth and reproduction of Echinostoma caproni (Trematoda) in the ICR Mouse. J. Parasitol., 77, 640-642.

HUFFMAN, J. E. AND FRIED, B. 1990. Echinostoma and Echinostomiasis. Adv. Parasitol., 29, 215-269.

JAIN, s. K. 1976. Evolution of inbreeding in plants. Ann. Rev. Ecol. Syst., 7, 469-495.

JARNE, P. AND CHARLESWORTH, D. 1993. The evolution of selfing rate in functionally hermaphrodite plants and animals. Ann. Rev. Ecol. Syst., 24, 441-466.

JARNE, P. VIANEY-LIAUD, M. AND DELAY, B. 1993. Selfing and outcrossing in hermaphrodite freshwater gastropods (Basommatophora): where, when and why. Biol. J. Linn. Soc., 49, 99-125.

KUMARATILAKE, L. M., THOMPSON, R. C. A., ECKERT, J. AND ALESSSANDRO, A. D. 1986. Sperm transfer in Echinococcus (Cestoda: Taeniidae). Z. Parasitenkd., 72, 265-269.

MANLy, B. F. J. 1987. The Statistics of Natural Selection. Chapman and Hall, London.

MAYNARD SMITH, J. 1989. Evolutionary Genetics. Oxford University Press, Oxford.

NOLLEN, P. M. 1983. Patterns of sexual reproduction among parasitic platyhelminths. Parasitology, 86, 99-120.

NOLLEN, P. M. 1990. Echinostoma caproni mating behavior and the timing of development and movement of reproductive cells. J. Parasitol, 76, 784-789.

NOLLEN, P. M. 1993. Echinostoma trivolis: mating behavior of adults raised in hamsters. Parasitol. Res., 79, $130-132$.

PASTEUR, N., PASTEUR, G. BONHOMME, F., CATALAN, J. AND BRITTON-DAVIDIAN, J. 1987. Manuel Technique de Génétique par Électrophorèse des Protéines. Technique et Documentation, Lavoisier, Paris.

PRICE, P. W. 1977. General concepts on the evolutionary biology of parasites. Evolution, 31, 405-420.

PRICE, P. W. 1980. Evolutionary Biology of Parasites. Princeton University Press, NJ.

RAYMOND, M. AND ROUSSET, F. 1995. GENEPOP (ver. 1.2): an exact test for population differentiation. Evolution (in press).

RENAUD, F. AND GABRION, C. 1988. Speciation of cestoda. Evidence for two sibling species in the complex Bothrimonus nylandicus (Schneider, 1902) (Cestoda: Cyathocephalidea). Parasitology, 97, 139-147.

RENAUD, F., GABRION, C. AND PASTEUR, N. 1983. Le complexe Bothriocephalus scorpii (Mueller, 1776): différenciation par électrophorèse enzymatique des espèces parasites du Turbot (Psetta maxima) et de la Barbue (Scophthalmus rhombus). C. r. Acad. Sci. Paris,

(C) The Genetical Society of Great Britain, Heredity, 77, 1-8. 
296, 127-129.

RENAUD, F., GABRION, c. AND PASTEUR, N. 1986.

Geographical divergence in Bothriocephalus (Cestoda) of fishes demonstrated by enzyme electrophoresis. Int. J. Parasitol., 16, 553-558.

Renaud, F., Coustau, C., Le BRun, N. ANd moulia, $C$. 1992. Parasitism in host hybrid zone. Res. Rev. Parasitol., 52, 13-20.

REVERsat, J, RENAUd, F. AND MAILlard, C. 1989. Biology of parasite populations: the differential specificity of the genus Helicometra Odhner, 1902 (Trematoda: Opecoelidae) in the Mediterranean Sea demonstrated by enzyme electrophoresis. Int. J. Parasitol., 19, 885-890.

RICE, W. R. 1989. Analyzing tables of statistical tests. Evolution, 43, 223-225.

ROHDE, K. 1979. A critical evaluation of intrinsic and extrinsic factors responsible for niche restriction in parasites. Am. Nat, 114, 648-671.

ROLLINSON, D., KANE, R. A. AND LINES, J. R. L. 1989. An analysis of fertilization in Bulinus cernicus (Gastropoda: Planorbidae). J. Zool. Lond, , 217, 295-310.
RYLAND, J. S. AND BISHOP, J. D. D. 1990. Prevalence of cross-fertilization in the hermaphroditic compound ascidian Diplosoma listerianum. Mar. Ecol. Prog. Ser. 61, $125-132$.

SOKAL, R. R. AND ROHLF, F. J. 1981. Biometry, 2nd edn. Freeman, New York.

TOMLinson, J, 1966. The advantages of hermaphroditism and parthenogenesis. J. Theor. Biol., 11, 54-58.

VOLTZ, A., RICHARD, J., PESSON, B. AND JOURDANE, J. 1986. Etude chimiotaxonomique du genre Echinostoma: Comparaison d'une souche isolée du Cameroun ( $E$. $\mathrm{sp}$.) à deux espèces africaines (E. caproni et $E$. togoensis). Ann. Parasitol. Hum. Comp., 61, 617-623.

vOlTZ, A., RICHARD, J. AND PESSON, B. 1987. A genetic comparison between natural and laboratory strains of Echinostoma (Trematoda) by isoenzymatic analysis. Parasitology, 95, 471-477.

VOLTZ, A., RICHARD, J., PESSON, B. AND JOURDANE, J. 1988. Isoenzyme analysis of Echinostoma liei: comparison and hybridization with other African species. Exp. Parasitol., 66, $13-17$. 